\title{
AVALIAÇÃO DA ESTABILIDADE TÉRMICA DE PECTINASES COMERCIAIS IMOBILIZADAS E TRATADAS COM FLUIDO PRESSURIZADO
}

\author{
C. E. DEMAMAN ORO ${ }^{1}$, I. GAIO ${ }^{1}$, E. VALDUGA ${ }^{1}$, A. FURIGO JR. ${ }^{2}$, N. L. D. NYARI ${ }^{1}$, \\ I. A. FERNANDES ${ }^{1}$, A. M. GRABOSKI ${ }^{1}$, N. A. DARONCH ${ }^{1}$ \\ ${ }^{1}$ Universidade Regional Integrada do Alto Uruguai e das Missões, Faculdade de Engenharia \\ de Alimentos \\ ${ }^{2}$ Universidade Federal de Santa Catarina, Departamento de Engenharia Química e Alimentos \\ E-mail para contato: carolinae.oro@hotmail.com
}

\begin{abstract}
RESUMO - Pectinases, ou enzimas pectinolíticas, são produzidas por um grande número de bactérias, leveduras e fungos filamentosos, insetos, nematódeos e plantas, a fim de degradar - para a obtenção de fonte de carbono, ou para modificar, fruto em amadurecimento - o heteropolissacarídeo pectina. A escolha de um processo de imobilização para uma dada enzima depende de fatores essenciais do processo, tais como os substratos utilizados, os tipos de reações e as configurações do reator, exigindo um projeto adequado para atender às necessidades da reação. As preocupações ambientais têm alertado a comunidade científica no sentido de investigar novas maneiras de diminuir o uso de solventes orgânicos voláteis. Para este efeito, o uso de fluidos supercríticos aparece como uma alternativa interessante. No presente estudo, a enzima polimetilgalacturonato liase (PMGL) foi submetida a tratamento com Gás Liquefeito de Petróleo (GLP) e a sua estabilidade térmica foi medida. $\mathrm{O}$ trabalho teve como objetivo avaliar a estabilidade térmica de pectinases comerciais imobilizadas e tratadas com fluido pressurizado.
\end{abstract}

\section{INTRODUÇÃO}

O termo geral "pectina" designa ácidos pectínicos solúveis em água, com quantidade variável de grupos metil éster e um grau de neutralização capaz de formar gel com açúcares e ácidos em condições determinadas (SAKAI et al. 1993).

No presente estudo, a enzima polimetilgalacturonato liase (PMGL) foi investigada. Segundo Kashyap et al. (2001), a enzima polimetilgalacturonato liase (PMGL) pertence ao grupo das pectinases despolimerizantes, podendo ser a endo-PMGL ou endo-pectina liase (E.C.4.2.2.10), que hidrolisa as ligações glicosídicas entre resíduos de ácidos galacturônicos por um mecanismo de trans-eliminação e/ou a exo-PMGL ou exo pectina liase, que hidrolisa a pectina, sequencialmente, por trans-eliminação.

A crescente ênfase no uso de biocatalisadores devido às suas propriedades favoráveis, tais como condições amenas e ambientalmente compatíveis de reação e sua alta especificidade, têm resultado num aumento do uso de enzimas imobilizadas, pois a interação 
entre suporte e a enzima podem alterar favoravelmente as suas propriedades físicas e químicas (BASRI et al., 1996).

As principais vantagens do GLP pressurizado com relação ao $\mathrm{CO}_{2}$ supercrítico são: seu preço relativamente mais baixo; a observação de que os principais gases que o compõe, propano e n-butano, não apresentam efeito deletério na atividade da enzima, como acontece com o dióxido de carbono supercrítico (HABULIN; KNEZ, 2001), além da possibilidade de se operar em pressões mais baixas quando comparado com o $\mathrm{CO}_{2}$.

O presente trabalho teve como objetivo avaliar a estabilidade térmica de pectinases comerciais imobilizadas e tratadas com fluido pressurizado.

\section{MATERIAL E MÉTODOS}

\subsection{Enzimas}

Para a condução do estudo, foram utilizadas duas pectinases comerciais (Pectinex ${ }^{\circledR}$ MASH e Pectinex ${ }^{\circledR}$ Ultra SP-L), na forma livre, que foram gentilmente cedidas pela empresa LNF Latino Americana Ltda. Ambas são enzimas produzidas por fermentação submersa pelos fungos filamentosos Aspergillus aculeatus e Aspergillus niger.

\subsection{Reagentes}

O gás liquefeito de petróleo foi fornecido pela Petrobras e é constituído por uma mistura de propano $(50,3 \%)$, n-butano $(28,4 \%)$, isobutano $(13,7 \%)$, etano $(4,8 \%)$ e outros componentes secundários (metano, pentano, isopentano, entre outros). Os demais reagentes empregados foram: Solução de Cloreto de Cálcio $75 \mathrm{mmol}\left(\mathrm{CaCl}_{2}\right)$; Solução Tampão de Oxalato de Sódio; Alginato de Sódio; Solução Tampão de Acetato de Sódio 100 mM, pH 4,5; Solução de Pectina 1,0\% em tampão Tris-HCl 0,05 M, pH 4,5; Solução de Cloreto de Cálcio 0,01M $\left(\mathrm{CaCl}_{2}\right)$; Solução de Sulfato de Zinco hepta hidratado a $9 \%\left(\mathrm{ZnSO}_{4} 7 . \mathrm{H}_{2} \mathrm{O}\right)$; Solução de Hidróxido de Sódio 0,5M ( NaOH); Solução de Ácido Tiobarbitúrico 0,04M $\left(\mathrm{C}_{4} \mathrm{H}_{4} \mathrm{~N}_{2} \mathrm{O}_{2} \mathrm{~S}\right)$; Solução de Ácido Clorídrico 0,1M ( $\mathrm{HCl})$;

\subsection{Imobilização da enzima em suporte gelatina-alginato}

Na imobilização foi empregado gelatina e solução de $\mathrm{CaCl}_{2}$, segundo metodologia por Shen (2011) e Vargas (2013), com modificações. Para o preparo da solução gel, adicionou-se $10 \mathrm{~mL}$ de solução tampão oxalato de sódio e $2 \%$ de alginato de sódio, que foram aquecidos $\left(\sim 60^{\circ} \mathrm{C}\right)$ até a dissolução. Após o resfriamento da solução gel, acrescentou-se $3 \mathrm{~mL}$ de extrato enzimático (Pectinex ${ }^{\circledR}$ MASH e Pectinex ${ }^{\circledR}$ Ultra SP-L). O gel formado foi gotejado em $50 \mathrm{~mL}$ de solução de $\mathrm{CaCl}_{2} 75 \mathrm{mmol} / \mathrm{L}$ previamente preparado com $1 \%$ de gelatina. Em seguida, as microesferas foram lavadas com $100 \mathrm{~mL}$ de água destilada e $100 \mathrm{~mL}$ de tampão acetato de sódio $(100 \mathrm{mM}, \mathrm{pH} 4,5)$ e então armazenada a $4^{\circ} \mathrm{C}$ em recipiente de plástico com tampa, este recipiente plástico com a enzima foi colocado dentro de um vidro com sílica gel. 


\subsection{Aparato experimental para tratamento da enzima em fluido pressurizado}

O equipamento consiste basicamente de um reservatório de solvente, um banho termostático, uma bomba de seringa (ISCO 260 D), uma reator de aço inoxidável com um volume interno de $50 \mathrm{~mL}$, um transdutor de pressão absoluta (Smar, LD301) equipado com um programador portátil (Smar, HT201) com uma precisão de $\pm 0,4$ bar. O diagrama esquemático do equipamento é apresentado na Figura 1. Todas as linhas de montagem experimental empregaram tubulações de aço inoxidável com diâmetro externo 1/16" (HIP). Uma "check valve" (HIP 15-41AF1-T316SS) foi colocada entre a bomba e o reservatório de solvente para evitar o refluxo de solvente pressurizado.

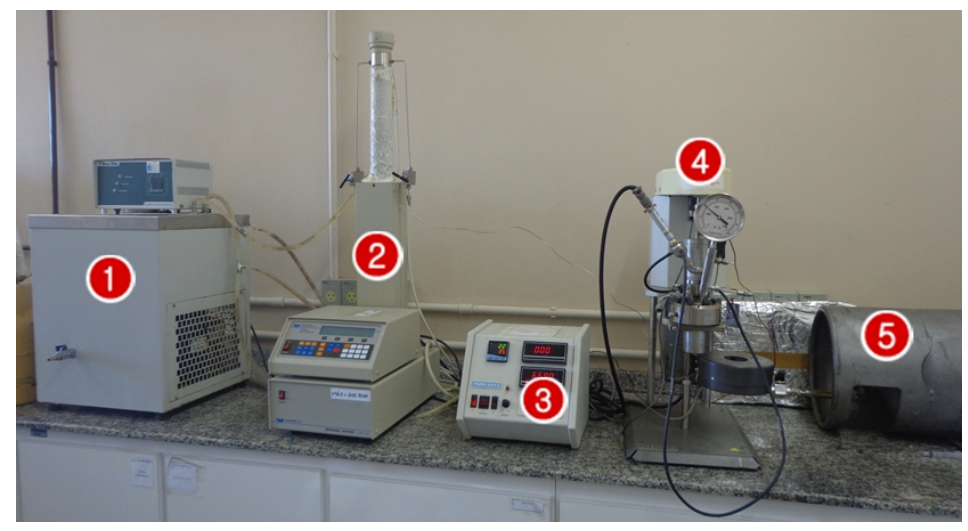

Figura 1- Aparato utilizado no tratamento das enzimas com o fluido pressurizado. 1- Banho Termostático; 2Bomba de seringa; 3- Transdutor de pressão, temperatura e agitação; 4- Reator/célula de aço equipada com manômetro e manta de aquecimento; 5- Cilindro contendo gás GLP.

\subsection{Determinação da atividade enzimática}

A atividade enzimática era determinada antes (atividade inicial) e após (atividade final) ao tratamento com fluido pressurizado. A atividade residual foi determinada de acordo com o exposto na Equação 1 e a Equação 2 refere-se as etapas de avaliação da estabilidade a diferentes temperaturas de armazenamento.

$$
\text { Aividade residual }(\%)=\frac{\text { Atividade após pressurização }}{\text { Atividade antes da pressurização }} \times 100
$$

Aividade residual $(\%)=\frac{\text { Atividade após armazenamento }}{\text { Atividade inicial }} \times 100$ 
A atividade da pectina liase foi determinada segundo método de Ayers et al. (1966), descrito por Pitt (1988), com algumas modificações, onde determinou-se os produtos insaturados finais da degradação da pectina e do ácido tiobarbitúrico. Uma unidade da atividade enzimática foi definida como a quantidade de enzima que causa a mudança de 0,01 na absorbância a $550 \mathrm{~nm}$, nas condições do ensaio (Equação 3).

Atividade $(U / m L)=\frac{\Delta a b s}{0,01}$

A Figura 2 abaixo mostra resumidamente como foi feita a medida da atividade enzimática.

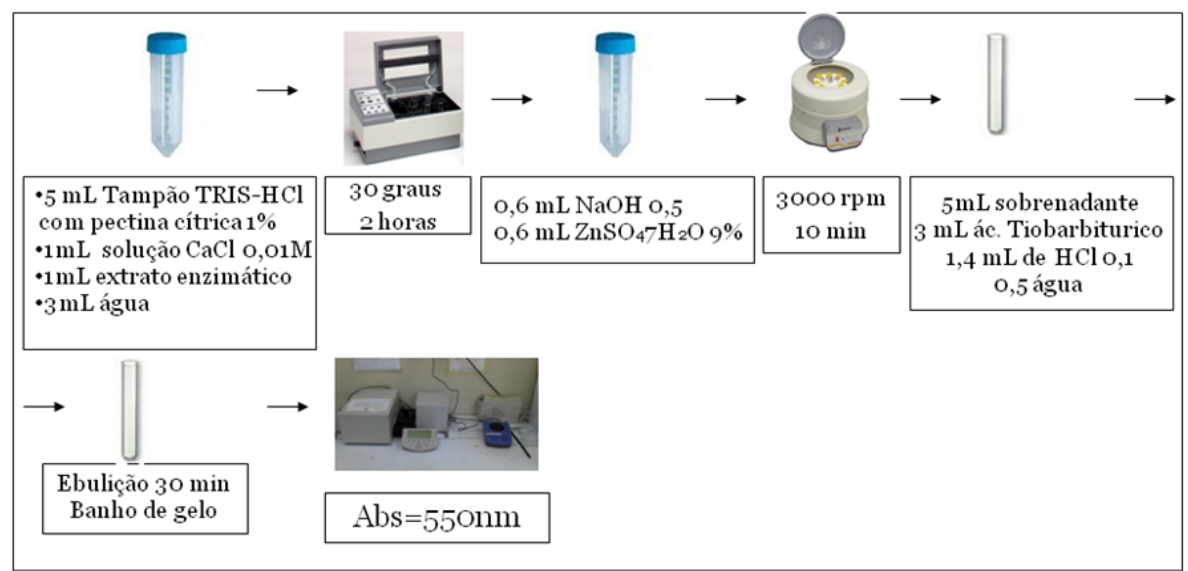

Figura 2- Esquema da determinação da atividade da enzima PMGL.

\section{RESULTADOS E DISCUSSÃO}

A Figura 3 mostra a estabilidade da enzima polimetilgalacturonato liase (PMGL) Pectinex ${ }^{\circledR}$ MASH imobilizada e pressurizada utilizando gás GLP (Pressão de 30 bar, tempo de 1 hora e taxa de despressurização de $100 \mathrm{bar} / \mathrm{min}$ ).

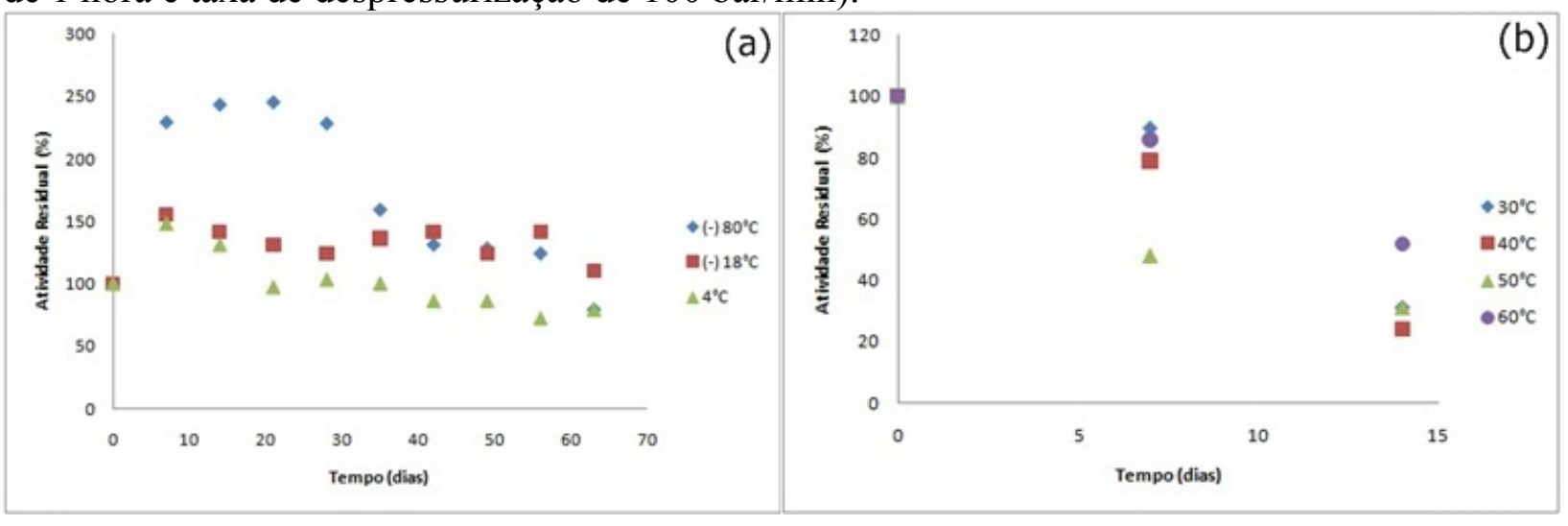

Figura 3- Estabilidade térmica da enzima polimetilgalacturonato liase (PMGL) Pectinex® MASH imobilizada e pressurizada utilizando GLP nas temperaturas baixas (a) e temperaturas altas (b). 
Observa-se que a atividade residual apresentou um valor entre 103 a $245 \%$ para a enzima pressurizada e acondicionada nas temperaturas baixas $\left(-80\right.$ a $\left.4^{\circ} \mathrm{C}\right)$ durante os 28 primeiros dias, indicando desta forma um acréscimo de atividade em relação a atividade inicial e mantendo-se aproximadamente $70 \%$ da sua atividade residual por cerca de 63 dias. Porém, quando a mesma enzima foi armazenada em temperaturas altas ( 30 a $\left.60^{\circ} \mathrm{C}\right)$ mostrou um efeito contrário se comparado ao resultado obtido pela enzima apenas imobilizada, no qual a atividade residual foi de $88 \%$ em 21 dias na temperatura de $40^{\circ} \mathrm{C}$, enquanto que a enzima imobilizada e tratada com GLP aos 14 dias mostrou atividade máxima de $52 \%$ para a temperatura de $60^{\circ} \mathrm{C}$ (Figura 3b). Ou seja, pode-se inferir que o tratamento com GLP apresentou um efeito negativo na estabilidade desta enzima.

A estabilidade térmica para a enzima polimetilgalacturonato liase (PMGL) Pectinex ${ }^{\circledR}$ Ultra SP-L imobilizada e pressurizada (Pressão de 190 bar, tempo de 1 hora e taxa de despressurização de 20 bar/min) utilizando GLP é apresentada na Figura 4.

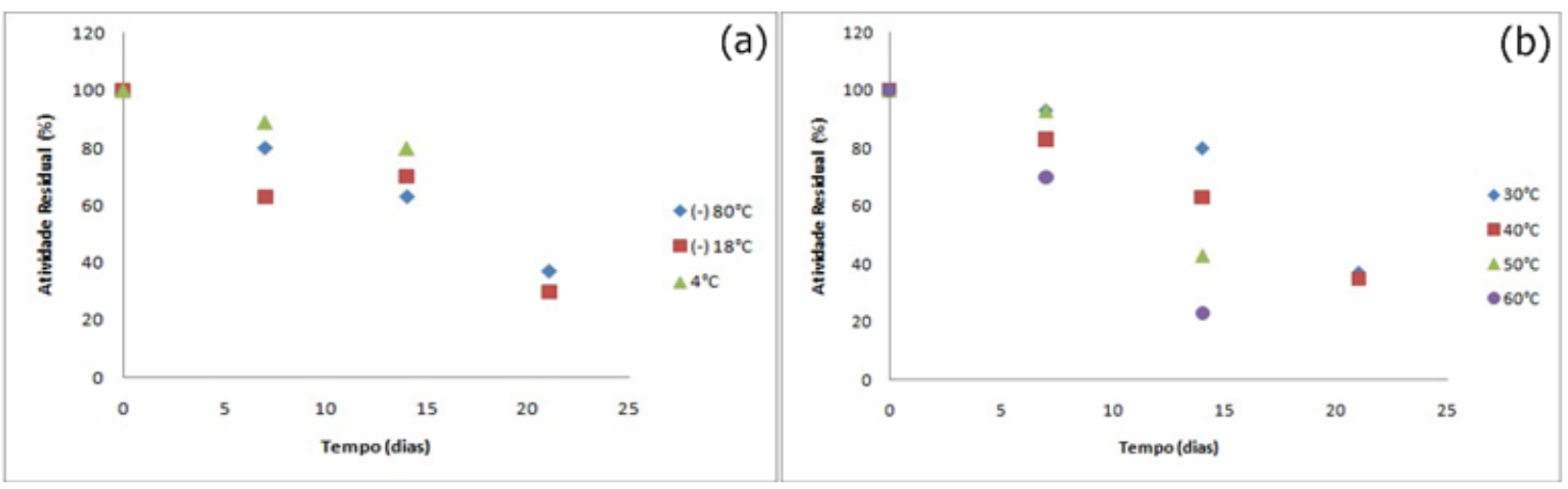

Figura 4- Estabilidade térmica para a enzima polimetilgalacturonato liase (PMGL) Pectinex ${ }^{\circledR}$ Ultra SP-L imobilizada e pressurizada utilizando GLP nas temperaturas baixas (a) e temperaturas altas (b).

A estabilidade térmica nas baixas temperaturas (Figura 4a), foi de aproximadamente $50 \%$ da sua atividade inicial aos 14 dias para a polimetilgalacturonato liase (PMGL) Pectinex ${ }^{\circledR}$ Ultra SP-L imobilizada e pressurizada utilizando GLP. Esta enzima em particular mostrou-se mais frágil quando comparada a enzima Pectinex ${ }^{\circledR}$ MASH (Figura 3).

A termoestabilidade de uma enzima refere-se tanto à termoestabilidade dinâmica $\mathrm{e}$ quanto à estabilidade cinética. A termoestabilidade dinâmica $(\mathrm{T} m)$ representa $50 \%$ da enzima desdobrada e a termoestabilidade cinética reflete a meia vida $\left(\mathrm{T}^{1} / 2\right)$ da enzima, a uma determinada temperatura. Essa termoestabilidade está diretamente associada ao dobramento da proteína, o qual é estabilizado por equilíbrio entre forças de dobramento e de desdobramento (energia de estabilização da enzima $\Delta G s t a b$ ) que é representado por $\Delta G s t a b=$ $\Delta H s t a b-T . \Delta S s t a b$, onde $\Delta \mathrm{H}=$ entalpia de estabilização (dobrado) e $\Delta \mathrm{S}=$ entropia (desdobrado) (SARABOJI, et al., 2005).

A proteína nativa é mantida por um delicado balanço de forças não covalentes, como pontes de hidrogênio, pareamento de íons, interações hidrofóbicas e força de van der Waals. Com o aumento da temperatura, essas interações são rompidas e a proteína se desdobra (ANFINSEN, 1973). 


\section{CONCLUSÃO}

O presente trabalho teve como objetivo avaliar a estabilidade térmica de pectinases comerciais imobilizadas e tratadas com fluido pressurizado. A enzima polimetilgalacturonato liase (PMGL) Pectinex ${ }^{\circledR}$ MASH mostrou ótimos resultados quando imobilizada com gelatina-alginato para todas as temperaturas propostas. Quando a enzima imobilizada foi tratada com gás GLP observou-se um efeito contrário para a estabilidade em altas temperaturas. Isso pode estar associado ao desdobramento da proteína, mas são necessários estudos mais aprofundados do efeito do GLP sobre a enzima. A polimetilgalacturonato liase (PMGL) Pectinex ${ }^{\circledR}$ Ultra SP-L obteve um aumento na sua atividade residual para as altas temperaturas.

Como foi observado, é preciso um estudo mais aprofundado sobre os efeitos do gás GLP sobre a atividade das enzimas pécticas.

\section{REFERENNCIAS}

ANFINSEN, C. B.; Principles that govern the folding of protein chains. Science, 181. 223230. (Nobel Lecture), 1973.

BASRI, M.; YUNUS, W.Z.W.; YOONG, W.S.; AMPON, K.; RAZAK, C.N.A.; SALLEH, A.B. Immobilizatio of lipase from Candida rugosa on synthetic polymer beads for use in the synthesis of fatty esters. Journal of Chemical Technology and Biotechnology. 1996: v.6: $169-173$.

HABULIN, M.; KNEZ, Z. Activity and stability of lipases from different sources in supercritical carbon dioxide and near-critical propane, Journal of Chemical Technology \& Biotechnology, v. 76, p. 1260-1266, 2001.

KASHYAP, D. R.; VOHRA, P. K.; CHOPRA, S.; TEWARI, R. (2001). Applications of pectinases in the commercial sector: a review. Bioresource Technology, 77:215-227.

SAKAI, T.; SAKAMOTO, T.; HALLAERT, J.; VANDAMME, E. (1993). Pectin, pectinase and protopectinase: production, properties and applications. Advances in Applied Microbiology, 39: 213-294.

SARABOJI, K.; GROMINHA, M. M.; Ponuswany, M. N.; International Journal of Biological Macromolecules . 2005, 35, 211. 